\title{
Structure of Size and Reproduction of Green Iguanas (Iguana iguana) in the Brazilian Pantanal
}

\author{
Zilca Campos ${ }^{1}$ and Arnaud L. J. Desbiez ${ }^{2}$ \\ 'Embrapa Pantanal, CP 109,CEP 79320-900, Corumbá, MS, Brazil (zilca.campos@embrapa.br) \\ ${ }^{2}$ Royal Zoological Society of Scotland, Murrayfield, Edinburgh, EH12 6TS, Scotland
}

Photographs by the senior author.

$\mathrm{T}$

The Green Iguana (Iguana iguana) is widely distributed in Central and South America (Divers1995). This arboreal lizard generally occurs in vegetation near bodies of water. Much of its time is spent in the trees, but it descends to the ground for foraging, travel, to dig holes, and to lay its eggs (Rodda 1990). In Brazil, the species is known as the Green Lizard or Sinimbu (Fig. 1), and it occurs in Amazonia, the Caatinga, and the Pantanal. Although few studies have been conducted on its ecology in Brazil, some aspects of its reproductive biology have been reported in the Pantanal (Campos 2004) and Amazonia (Haller and Roberts 2005). The Green Iguana's reproductive cycle is annual, with testicular development occurring between July and September (Ferreira et al. 2002) and aggressive behavior between males observed

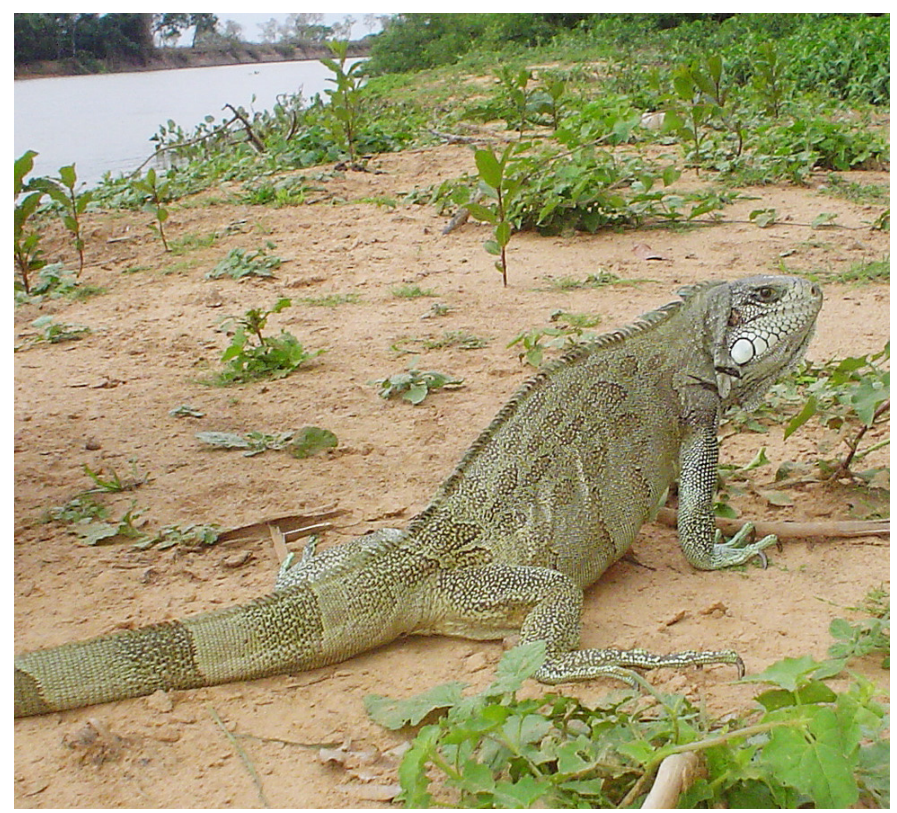

Fig. 1. Adult female Green Iguana (Iguana iguana) on the beach of the Cuiabá River in the Pantanal of Brazil. in May (Desbiez and Campos 2009). Iguanas reproduce in groups or alone and can build complex systems of holes and galleries (Rand and Dugan 1983). Communal nesting has been observed in these tunnels (Rand 1968, Mora 1989). In the Pantanal, nests are dug along riverbanks or on sandy beaches during the end of the dry season when river levels are lowest (Campos 2004). The purpose of this study was to characterize Green Iguana reproduction and gather baseline data on population structure in the Pantanal.

\section{Methods}

The study was conducted in the Private Natural Heritage Reserve-SESC Pantanal (16³0'56.70”S, 56²2'35.05”W), which is located in the city of Barão de Melgaço, North

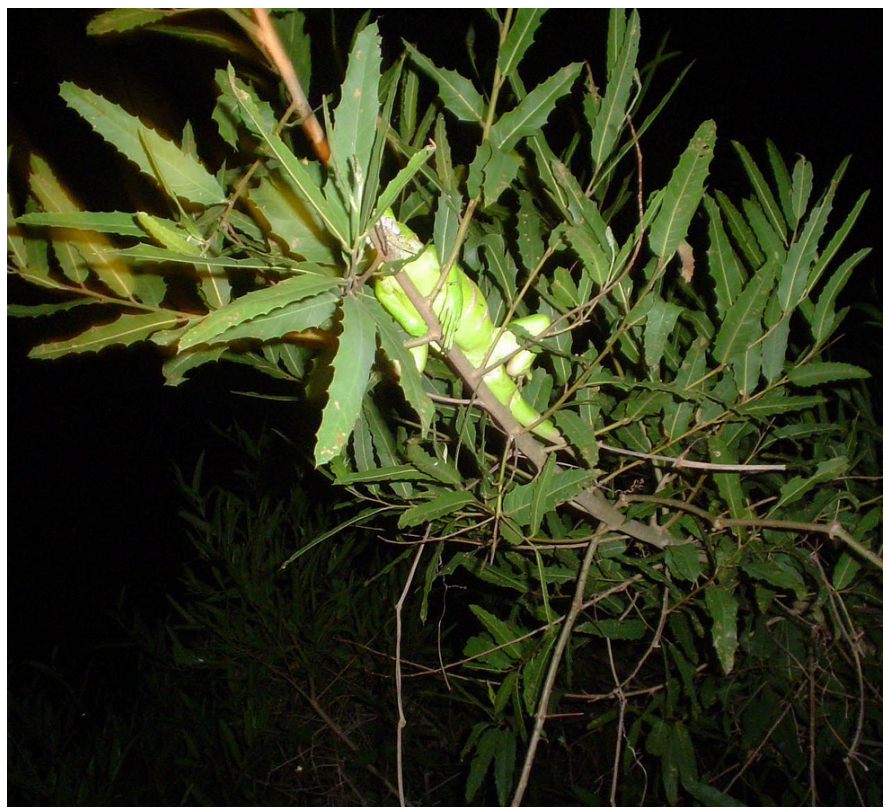

Fig. 2. Sleeping Green Iguana (Iguana iguana) along the bank of the Cuiabá River in the Pantanal of Brazil. 
Pantanal. The reserve fully protects an area of more than 100,000 ha between São Lourenço and the Cuiabá River. We counted and marked Green Iguanas during nocturnal surveys from boats every year between 2005 and 2009 on the Cuiabá River and small tributaries in the SESC Pantanal. We located iguanas sleeping on branches of trees and shrubs along riverbanks at night using a sealed-beam lamp connected to a 12-volt battery (Fig. 2). Individuals were carefully and quietly approached and captured using a lasso tied to a bamboo stick or by hand, depending on time and height in the vegetation. To avoid or minimize stress, a capture must be executed before iguanas "wake up" and leap into the water. We immobilized captured lizards by sealing their eyes and mouths with tape. We recorded snout-vent length (SVL), total length (TL), and body mass. Sexes of adult iguanas are readily determined. Males have large femoral pores and well developed nuchal and dorsal crests, whereas females have small pores and the nuchal and dorsal spines are smaller and worn (Dellinger and von Hegel 1990). Hatchlings (SVL < 20 cm; Fig. 3) were not sexed. All captured iguanas were marked with numbered aluminum tags (National Band) set in the crests of the neck and released onto the branches where they were captured.

We located nests from August through September 2006, 2008 , and 2009 by systematically exploring the beaches of the Cuiabá River and its tributaries. We excavated each nest to find the egg chamber. Eggs were counted, measured (length, width), and weighed. Females found in burrows were captured and measured as above.

Means are presented \pm one standard deviation. For all statistical tests, $\mathrm{a}=0.05$.

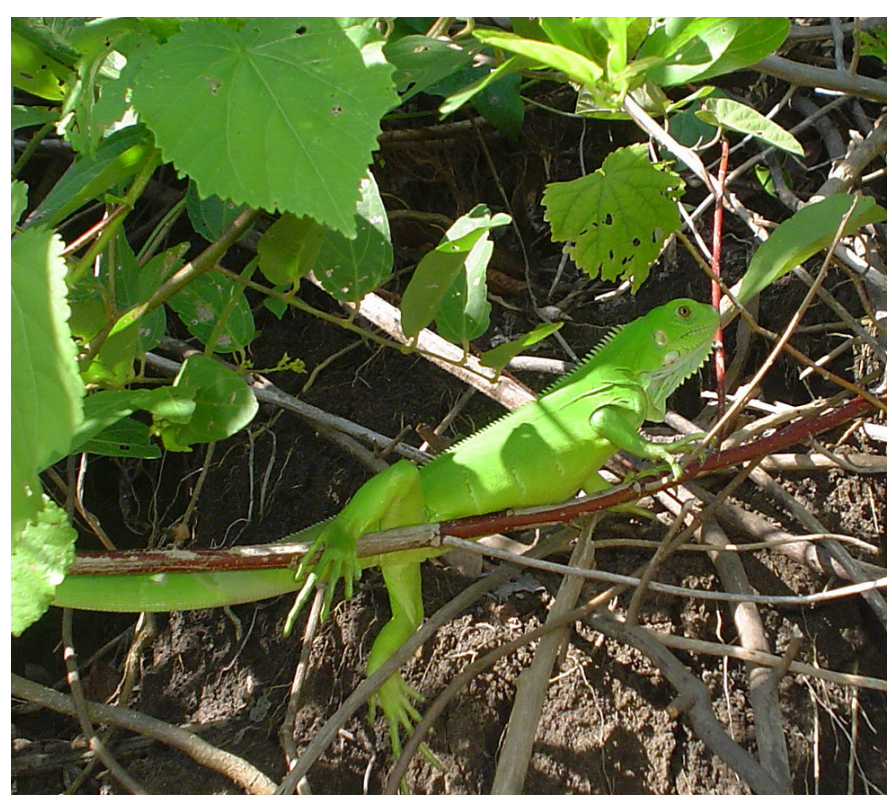

Fig. 3. Hatchling Green Iguana (Iguana iguana) along the Cuiabá River in the Pantanal of Brazil.

\section{Results and Discussion}

In four years of study, we captured 130 Green Iguanas (67 females, 39 males, and 24 hatchlings; Fig. 4). Mean adult female SVL was $29.2 \pm 6.1 \mathrm{~cm}(20.5-39.0 \mathrm{~cm})$, mean adult male SVL was $26.6 \pm 7.1 \mathrm{~cm}(20.0-45.5 \mathrm{~cm})$, and mean hatchling SVL was $15.7 \pm 2.8 \mathrm{~cm}(9.0-19.5 \mathrm{~cm})$. Mean adult female mass was $1.0 \pm 0.5 \mathrm{~kg}(0.19-2.23 \mathrm{~kg})$, mean adult male mass was $0.78 \pm 0.72 \mathrm{~kg}(0.22-3.1 \mathrm{~kg})$, and mean hatchling mass was $0.16 \pm 0.07 \mathrm{~kg}(0.02-0.28 \mathrm{~kg})$. Generally, TL was nearly three times SVL.

The mean height at which 34 sleeping females were captured was $1.6 \pm 1.4 \mathrm{~m}(0-5 \mathrm{~m}) ; 10$ males were captured at a mean height of $1.9 \pm 0.74 \mathrm{~m}(1-3 \mathrm{~m})$ and 11 hatchlings were captured at a mean height of $1.3 \pm 0.9 \mathrm{~m}(0.05-$ $3.0 \mathrm{~m})$. Adults slept significantly higher than hatchlings (Kolmogorov-Smirnov test; $\mathrm{D}=0.95 ; \mathrm{P}<0.0001$ ).

We found five nests (Fig. 5) during the reproductive season of 2005, 14 in 2006, five in 2008, and 20 in 2009. Nests were in simple or complex tunnels on the beaches of the Cuiabá River. In August 2006, we observed 10 females digging nests in sand on the beach, but only three had laid eggs (Table 1), including the female illustrated in Fig. 1. The mean depth of nests was $30.0 \pm 7.5 \mathrm{~cm}(2040 \mathrm{~cm})$. Mean number of eggs was $21.0 \pm 8.1(\mathrm{~N}=42 ; 5-41)$. Mean length and width of eggs was $44.7 \pm 1.9 \mathrm{~mm}(42.1-50.0 \mathrm{~mm})$ and $29.8 \pm 2.1 \mathrm{~mm}(26.5-33.1 \mathrm{~mm})$, respectively, and weight was $17.032 .0 \mathrm{~g}($ mean $=25.0 \pm 3.6 \mathrm{~g})$.

The presence of individuals of all size classes is suggestive of a stable population. We are unable to determine if the female-biased sex ratio $(-1: 2)$ in this population was real or an artifact of our collecting methods.

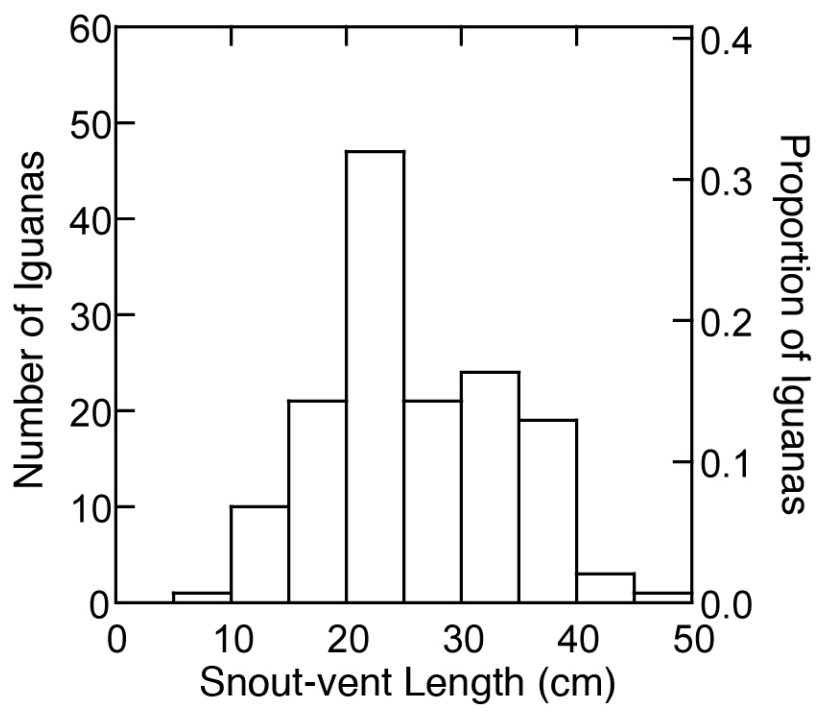

Fig. 4. Sizes of Green Iguanas (Iguana iguana) from along the Cuiabá River and its tributaries in the Pantanal of Brazil. 
Table 1. Size and reproductive status of adult female Green Iguanas (Iguana iguana) and the number of eggs/nest produced in the SESC Pantanal, September 2006.

\begin{tabular}{lccccc} 
Tag No. & SVL $(\mathbf{c m})$ & Tail $(\mathbf{c m})$ & Weight $(\mathbf{k g})$ & Eggs laid & Number of eggs \\
\hline 3509 & 39.0 & 92.0 & 1.30 & yes & 23 \\
\hline 3517 & 32.0 & 37.0 & 1.48 & no & - \\
\hline 3526 & 34.0 & 38.0 & 1.38 & no & - \\
\hline 3536 & 38.0 & 98.0 & 1.68 & yes & - \\
\hline 3538 & 33.0 & 8.0 & 1.34 & no & - \\
\hline 3541 & 34.5 & 90.0 & 1.24 & yes & 18 \\
\hline 3549 & 32.0 & 83.5 & 1.14 & yes & - \\
\hline 3550 & 33.0 & 15.0 & 0.92 & yes & - \\
\hline 3582 & 35.5 & 34.0 & 1.60 & no & - \\
\hline 3596 & 34.0 & 25.0 & 1.52 & no &
\end{tabular}

The reproductive period in our population begins around July with a peak in late August, in contrast to the region of the Paraguay River in the southern Pantanal, where reproduction occurs in November (Campos 2004). This can be explained best by differences in water levels in the two wetlands. Rains occur earlier in the north (our study) than

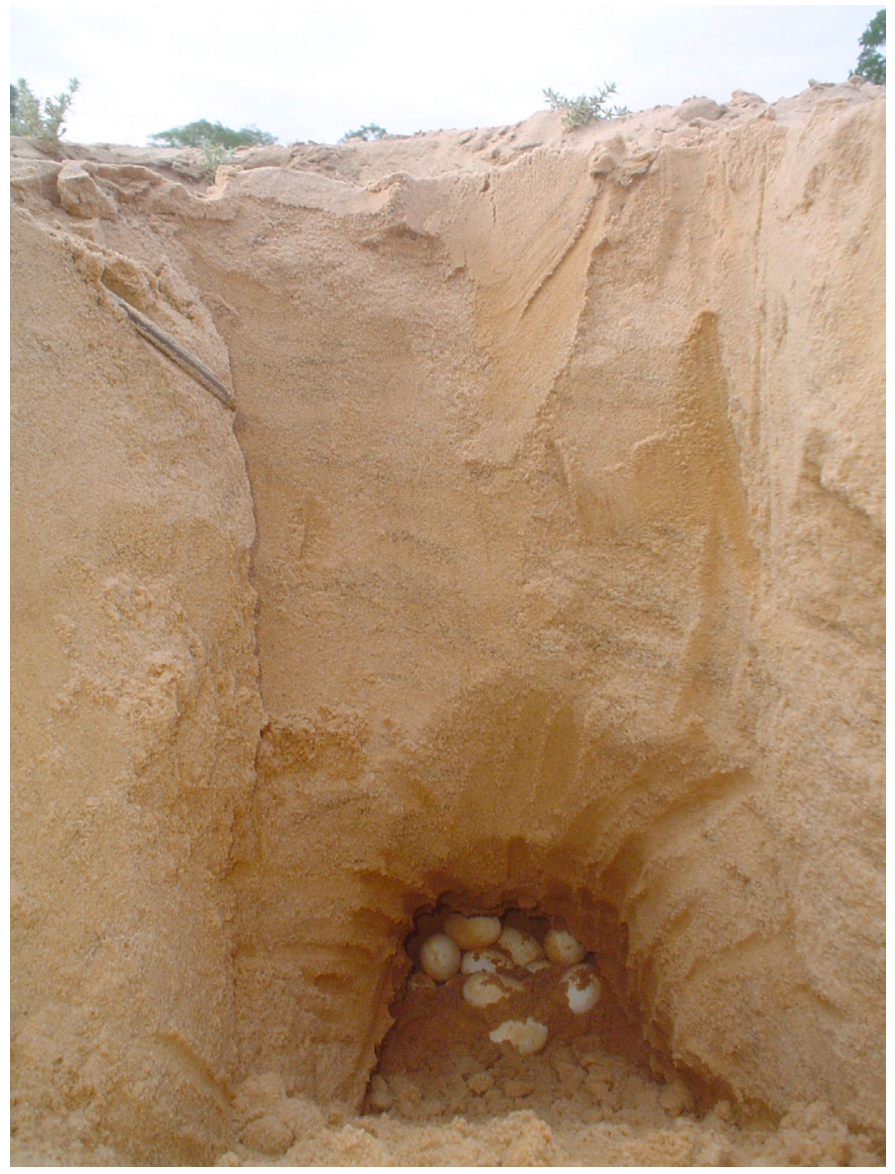

Fig. 5. An excavated nest of a Green Iguana (Iguana iguana) on the beach of the Cuiabá River in the Pantanal of Brazil. in the south, and might affect the start of the iguana breeding season. In Panama, Rand and Rand (1982) reported that reproductive activity of iguanas is influenced by external factors, and Ferreira et al. (2002) indicated that iguanas in the Pantanal are highly responsive to environmental conditions.

The habitat where most nests were dug in our study differed from that along the Paraguay River. Instead of sandy beaches along the banks of the Cuiabá River and its tributaries, nesting along the Paraguay River was in organic material and clay soil. The number of eggs also differed between the two sites. Along the Paraguay River in the southern Pantanal, Campos (2004) reported a mean number of about 14 eggs, whereas we found a mean of about 21 eggs along the Cuiabá River. However, Haller and Rodrigues (2005) found five nests with a mean of 24 eggs along the Amazon.

The identification, mapping, and protection of iguana nesting sites is an important conservation measure to ensure the reproduction and survival of the species. Beaches along the Cuiabá River are potentially vulnerable to and should be protected from possible disturbances and anthropogenic interference caused by the Manso hydroelectric dam.

\section{Acknowledgments}

We thank the RPPN SESC Pantanal, Embrapa Pantanal, and the Royal Zoological Society of Scotland for support. We also thank Dra. Emiko, Nivaldo, Afonso, Manoel, Claúdio and Alessandro for all of their help. The license number was 040/05-IBAMA/RAN.

\section{Literature Cited}

Campos, Z. 2004. Iguana iguana (Sinimbu). Reproduction. Herpetological Review 25:169.

Desbiez, A. and Z. Campos.2009. Iguana iguana (Green Iguana). Aggressive behavior. Herpetological Review 40:346.

Divers, S.J. 1995. The Green Iguana (Iguana iguana): A guide to successful captive management. British Herpetology Society Bulletin 51:6-26. 
Dellinger, T. and G. von Hegel. 1990. Sex identification through cloacal probing in juvenile Marine Iguanas (Amblyrhynchus cristatus). Journal of Herpetology 24:424-426.

Ferreira, A., I.A. Laura, and H. Dolder. 2002. Reproductive cycle of male Green Iguanas, Iguana iguana (Reptilia: Sauria: Iguanidae), in the Pantanal Region of Brazil. Brazilian Journal of Morphological Sciences 19:23-28.

Haller, E.C.P. and M.T.I. Rodrigues. 2005. Iguana iguana. Nests and nesting. Herpetological Review 36:319-320.

Mora, J.M. 1989. Eco-behavioral aspects of two communally nesting iguanines and the structure of their shared nesting burrows. Herpetologica 45:293-298.

Rand, A.S. 1968. A nesting aggregation of iguanas. Copeia 1968:552-561.
Rand, A.S. 1981. Clutch size in Iguana iguana in Central Panama, pp. 115-122. In: R.A. Seigel, L.E. Hunt, J.L. Knight, L. Malaret, and N.L. Zuschlag (eds.), Vertebrate Ecology and Systematics-A Tribute to Henry S. Fitch. Museum of Natural History, The University of Kansas, Lawrence.

Rand, A.S. and B.A. Dugan.1983. Structure of complex iguana nests. Copeia 1983:705-711.

Rand, A.S. and W.M. Rand. 1982. Variation in rainfall on Barro Colorado Island, pp. 47-59. In: E.G. Leigh, Jr., A.S. Rand, and D.M. Windsor (eds.), The Ecology of a Tropical Forest. Smithsonian Institution Press, Washington, D.C.

Rodda, G.H. 1990. Highway madness revisited: Roadkilled Iguana iguana in the Llanos of Venezuela. Journal of Herpetology 24:209-211. 